\title{
GENOTYPES OF JAPANESE ENCEPHALITIS VIRUS ISOLATED IN THREE STATES IN MALAYSIA
}

\author{
HIDEAKI TSUCHIE, KAZUMASA ODA, INDRA VYTHILINGAM, RAVINDRAN THAYAN, BALASUBRAMANIAM \\ VIJAYAMALAR, MANGALAM SINNIAH, JASBIR SINGH, TAKASHI WADA, HIROSHI TANAKA, \\ TAKASHI KURIMURA, AND AKIRA IGARASHI
}

Research Institute for Microbial Diseases, Osaka University, Osaka, Japan; Japan International Cooperation Agency, Tokyo, Japan; Institute for Medical Research, Kuala Lumpur, Malaysia; Veterinary Research Institute, Perak, Malaysia, Institute of Tropical Medicine, Nagasaki University, Nagasaki, Japan

\begin{abstract}
Two hundred forty nucleotides from the pre-membrane gene region of 12 Japanese encephalitis virus (JEV) strains isolated from three different regions of Malaysia from 1993 to 1994 were sequenced and compared with each other and with the JEV strains from different geographic areas in Asia. These 12 Malaysian isolates were classified into two genotypes. The four JEV strains isolated from Sarawak in 1994 and the four JEV strains isolated from Sepang, Selangor in 1993 were classified into one genotype that included earlier isolated strains from Malaysia (JE-827 from Sarawak in 1968 and WTP/70/22 from Kuala Lumpur in 1970). The four JEV strains from Ipoh, Perak in 1994 were classified into another genotype that included JEV strains isolated from northern Thailand and Cambodia. In an earlier report, $10 \mathrm{JEV}$ strains from Sabak Bernam, Selangor in 1992 were classified into the largest genotype that included strains isolated in temperate regions such as Japan, China, and Taiwan. The data indicate that at least three genotypes of JEV have been circulating in Malaysia.
\end{abstract}

Japanese encephalitis (JE) is a zoonotic disease that is transmitted by mosquitoes to domestic and wild animals and birds in most countries from eastern Asia to India. ${ }^{1,2}$ Domestic and migrating birds as well as pigs are effective amplifying hosts. Two billion people are currently living in the region and approximately 50,000 human JE cases are estimated to occur in Asia annually. ${ }^{3}$

Two distinct patterns of JE virus (JEV) transmission have been observed, epidemic and endemic. In general, the disease is epidemic in temperate regions of Asia and endemic in tropical regions. ${ }^{3}$ The reason(s) for these two distinct patterns is unknown, but one possible explanation is that there are regional differences in virulence among JEV strains. Antigenic and biochemical differences between JEV isolates have been demonstrated by several techniques. ${ }^{4-7}$ Comparative study of the nucleotide and deduced amino acid sequences of the core $(C)$, pre-membrane (pre-M), membrane $(\mathrm{M})$, and envelope (E) coding regions between five JEV strains, Nakayama-RFVL, Beijing-1, Kamiyama, Muar, and 691004, suggested that the Muar strain was the most structurally different from the other four strains, in agreement with the results using a hemagglutination inhibition test with JEV-species-specific monoclonal antibodies. ${ }^{4}$ Primer-extension sequencing of the genomic RNA template of JEV has provided new information on the geographic distribution, origin, and evolution of this virus. ${ }^{5,6}$ Two hundred forty nucleotides from the pre-M gene region of JEV isolates were analyzed, and the results showed the existence of four distinct JEV genotypes in Asia and suggested that genetic variations occurred among strains from different time periods in the same region. In addition, it has been recently reported that the nucleotide sequence of the pre-M protein region was the most variable among the structural protein genes $C$, pre-M, M, and E.?

The purpose of this study was to analyze $12 \mathrm{JEV}$ strains isolated in three regions of Malaysia from 1993 to 1994, and to explore their genetic relationships.

\section{MATERIALS AND METHODS}

Viruses. Adult mosquitoes were collected using CDC battery-operated light traps baited with $\mathrm{CO}_{2}{ }^{8}$ The traps were operated each night from 6:00 PM to 7:00 AM. The light traps were hung on trees or poles outdoors. Each pool of 50 mosquitoes of the same species was homogenized with $2 \mathrm{ml}$ of $0.2 \%$ bovine serum albumin in phosphate-buffered saline, pH 7.2, and was centrifuged at $3,000 \mathrm{rpm}$ for $15 \mathrm{~min}$ at $4^{\circ} \mathrm{C}$. Each supernatant was filtrated through a $0.22-\mu \mathrm{m}$ filter. An aliquot of the supernatant was inoculated into a monolayer of Aedes albopictus C6/36 cells. ${ }^{9}$ The first screening of the JEV isolate was carried out by immunoperoxidase staining of infected cells using a JEV hyperimmune mouse serum. Their identification was done by reverse transcriptase-polymerase chain reaction (RT-PCR) amplification using JEVspecific primer pairs. ${ }^{8}$ The $12 \mathrm{JEV}$ isolates from Malaysia included in this study are listed in Table 1 . These consist of four JEV strains isolated from Selangor state (Sepang district) in 1993, four from Perak state (Kinta district) in 1994, and four from Sarawak state (Serian district). Four JEV strains were isolated from blood samples of pigs in Ipoh, Perak, and the others were isolated from mosquitoes in Selangor or Sarawak. A group of one-month-old piglets on a farm near Ipoh were selected randomly and kept in a separate pen. Heparinized blood samples were collected weekly and the sera were used for detection of antibody to JEV. Buffy coat cells were inoculated into C6/36 cells and cultured for 10 days. After three passages, the supernatant was inoculated intracerebrally into a litter of suckling mice. The brains of the suckling mice, which died within a week postinoculation, were collected, homogenized, and identified by a hemagglutination inhibition test using a mouse polyclonal antiserum against JEV. Stocks of each virus were prepared in a monolayer of Ae. albopictus C6/36 cells.

In our previous study, $10 \mathrm{JEV}$ strains were isolated from mosquito samples collected in Sabak Bernam, Selangor from May to November 1992, and no difference in the nucleotide 
TABLE 1

Isolation history of Japanese encephalitis virus strains used in this study

\begin{tabular}{|c|c|c|c|}
\hline Strain & Year & Location & Source* \\
\hline Nakayama $\dagger$ & 1935 & Nakayama, Japan & Human brain \\
\hline Beijing-1† & 1949 & Beijing, China & Human brain \\
\hline M-859† & 1967 & Cambodia & Cx. gelidus \\
\hline M-864† & 1967 & Cambodia & Cx. tritaeniorhynchus \\
\hline JE-827† & 1968 & Sarawak & Cx. tritaeniorhynchus \\
\hline WTP/70/22† & 1970 & Kuala Lumpur, Malaysia & Mosquito pool \\
\hline Ph.Ar384† & 1977 & Philippines & Cx. tritaeniorhynchus \\
\hline JKT-657† & 1978 & Java, Indonesia & Cx. tritaeniorhynchus \\
\hline JKT-1724† & 1979 & Java, Indonesia & Cx. tritaeniorhynchus \\
\hline JKT-2363† & 1979 & Java, Indonesia & Cx. tritaeniorhynchus \\
\hline JKT-8442† & 1980 & Bali, Indonesia & Cx. tritaeniorhynchus \\
\hline $\mathrm{JaOArS} 982+$ & 1982 & Osaka, Japan & Mosquito pool \\
\hline KE-093/83† & 1983 & Kampanghet, Thailand & Human brain \\
\hline B-1034/83t & 1983 & Chumporn, Thailand & Pig blood \\
\hline B-1065/83† & 1983 & Chumporn, Thailand & Pig blood \\
\hline Ph.An1242† & 1984 & Santo Cristo, Philippines & Pig blood \\
\hline B-2239† & 1984 & Kampanghet, Thailand & Pig blood \\
\hline B-2582† & 1985 & Kampanghet, Thailand & Pig blood \\
\hline MaKAr32292 & 1992 & Selangor, Malaysia & Cx. vishnui \\
\hline MaKAr92593 & 1993 & Selangor, Malaysia & Ae. butleri \\
\hline MaKAr93693 & 1993 & Selangor, Malaysia & Cx. gelidus \\
\hline MaKAr97593 & 1993 & Selangor, Malaysia & Cx. gelidus \\
\hline MaKAr158793 & 1993 & Selangor, Malaysia & Cx. tritaeniorhynchus \\
\hline MaSAr01994 & 1994 & Sarawak, Malaysia & Cx. tritaeniorhynchus \\
\hline MaSAr03194 & 1994 & Sarawak, Malaysia & Cx. tritaeniorhynchus \\
\hline MaSAr03594 & 1994 & Sarawak, Malaysia & Cx. tritaeniorhynchus \\
\hline MaSAr03894 & 1994 & Sarawak, Malaysia & Cx. tritaeniorhynchus \\
\hline MAPAV294 & 1994 & Perak, Malaysia & Pig blood \\
\hline MAPAV494 & 1994 & Perak, Malaysia & Pig blood \\
\hline MAPAV594 & 1994 & Perak, Malaysia & Pig blood \\
\hline MAPAV794 & 1994 & Perak, Malaysia & Pig blood \\
\hline
\end{tabular}

* Viruses were isolated from pig blood, Culex $(C x$.), or Aedes (Ae.) mosquitoes.

+ The genomes of these viruses have already been sequenced, and were used in our study for comparative analysis.

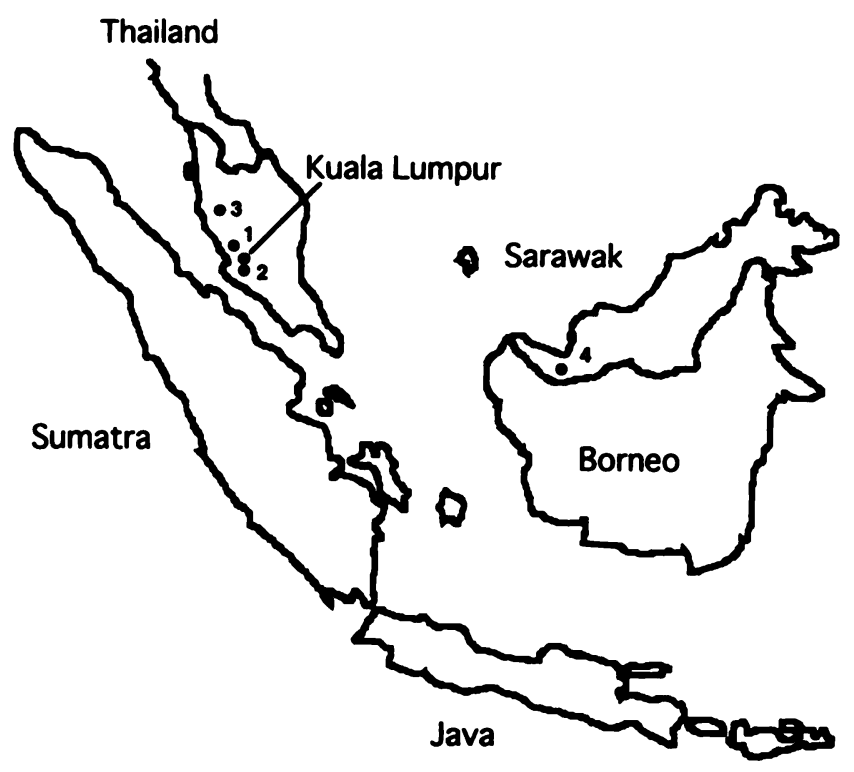

FIGURE 1. Map of Malaysia showing the approximate locations where the 22 JEV strains from Malaysia were isolated. 1 = Sabak Bernam District, Selangor studied in 1992; 2 = Sepang District, Selangor studied in 1993; 3 = Kinta District, Perak studied in 1994; 4 = Serian District, Sarawak studied in 1994. sequences of 240 nucleotides from the pre-M gene region was observed among the $10 \mathrm{JEV}$ strains. ${ }^{10}$ One of the 10 JEV strains, MaKAr32292, was also included in this study. The nucleotide sequences of JE-827 and WTP/70/22 have been reported as previous JEV isolates from Malaysia and were used for this comparison. ${ }^{5}$ The JaOArS982 virus strain, which has been cloned and completely sequenced, was used as a reference for sequence comparisons." Figure 1 shows the approximate locations where the 22 JEV strains from Malaysia were isolated. The nucleotide sequences of Beijing-1, Nakayama, Ph.Ar384, Ph.An1242, JKT-8442, M859, M864, B-2582, KE-093/83, B-2239, B-1034/83, B-1065/83, JKT-2363, JKT-1724, and JKT-657 have been previously reported and used in this study for dendrogramatic analysis. ${ }^{5.6 .12}$

Virus propagation and RNA extraction. The $\mathrm{C} 6 / 36$ cells were grown at approximately $28^{\circ} \mathrm{C}$ in $25-\mathrm{cm}^{2}$ plastic flasks containing Eagle's minimum essential medium with $10 \%$ heat-inactivated fetal calf serum and $0.2 \mathrm{mM}$ nonessential amino acids. After inoculation of each virus stock, the cultures were incubated for 5-7 days in maintenance medium (Eagle's minimum essential medium with $2 \%$ heat-inactivated fetal calf serum and $0.2 \mathrm{mM}$ nonessential amino acids) at approximately $28^{\circ} \mathrm{C}$, and the culture medium containing the virus was obtained. The RNA was extracted from the medium by using ISOGEN containing phenol and guanidine thiocyanate (Nippongene, Tokyo, Japan) as described previously. ${ }^{13}$ 


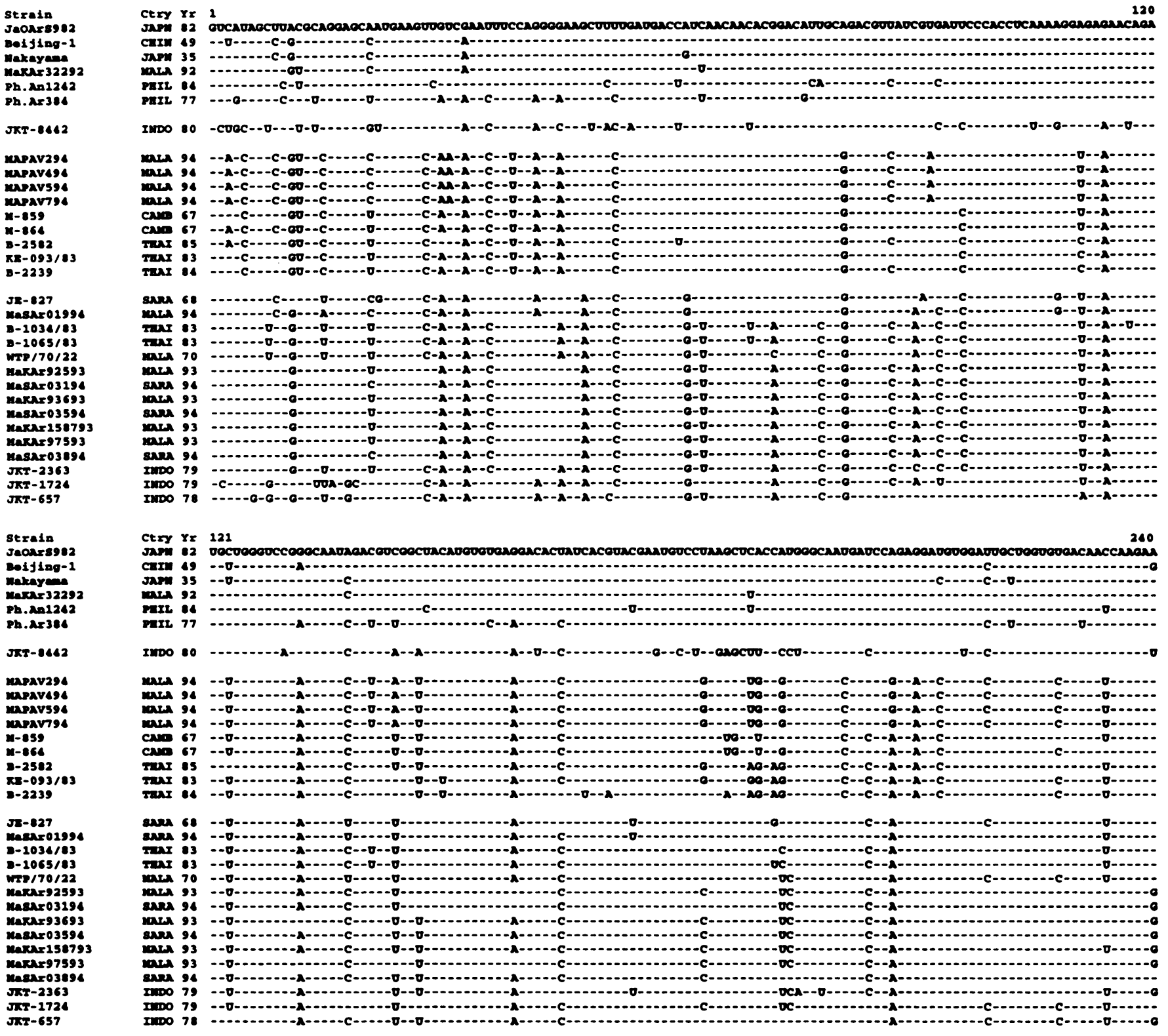

FIGURE 2. Comparison of the sequences of 240 nucleotides within the pre-membrane region for 31 Japanese encephalitis virus isolates. Strain numbers are listed first, followed by abbreviations for country (Ctry) of isolation and the last two digits of the year ( $\mathrm{Yr}$ ) of isolation (see Table 1). Nucleotide differences from JaOArS982, a virus isolated in Japan in 1982, are shown; dashes indicate identities. Nucleotide positions are numbered according to Sumiyoshi and others." The $\mathbf{2 4 0}$ nucleotides shown constitute the total sequence information used for each strain to construct the dendrogram in Figure 4. JAPN = Japan; CHIN $=$ China; MALA $=$ Malaysia; PHIL $=$ Philippines; INDO $=$ Indonesia; CAMB = Cambodia; THAI = Thailand; SARA = Sarawak

Synthesis of double-stranded DNA and sequencing of the amplified product. First-strand cDNA was obtained by reverse transcription of viral RNA and 50 pmoles of JEVspecific anti-genomic primer M-9914 (5' ${ }^{-739}$ TTGGAATGCCTGGTCCG $\left._{723^{-}} 3^{\prime}\right)$ in RT buffer (50 mM Tris- $\mathrm{HCl}$, pH 8.3, $50 \mathrm{mM} \mathrm{KCl}, 10 \mathrm{mM} \mathrm{MgCl}, 10 \mathrm{mM}$ DTT, $0.5 \mathrm{mM}$ spermidine, and $5 \mathrm{mM}$ dithiothreitol) containing $0.5 \mathrm{mM}$ each of the four deoxynucleotide triphosphates, 70 units of RNase inhibitor (Takara, Tokyo, Japan), and 100 units of avian myeloblastosis virus reverse transcriptase (Promega, Madison, WI). The cDNA was subjected to a 35-cycle amplification (denaturation at $95^{\circ} \mathrm{C}$ for $1 \mathrm{~min}$, annealing at $53^{\circ} \mathrm{C}$ for $1 \mathrm{~min}$, and elongation at $72^{\circ} \mathrm{C}$ for $1 \mathrm{~min}$ ) by PCR in PCR buffer (10 mM Tris- $\mathrm{HCl}$, pH 9.0, $1.5 \mathrm{mM} \mathrm{MgCl} 2,50 \mathrm{mM}$ $\mathrm{KCl}, 0.1 \%$ Triton X-100) using one-fifth of the cDNA-RNA hybrid mixture, $0.2 \mathrm{mM}$ each of the four deoxynucleotide triphosphates, 50 pmoles of the first primer, 50 pmoles of the second primer (JEM-1 $1^{5}$ of genomic-sense $5^{\prime}{ }_{-414}$ GGAAATGAAGGCTCAATCATGTG ${ }_{436} \mathbf{3}^{\prime}$ ), and 2.5 units of $\mathrm{Taq}$ DNA polymerase (Promega). The resulting amplified DNA products were cloned into the pBlueScript vector (Stratagene, La Jolla, CA) and sequenced using the Taq dye primer cycle sequencing kit (Applied Biosystems, Foster City, CA) in an Applied Biosystems Model 373A DNA sequencer.

Dendrogram and sequence similarity. Sequence information on 240 nucleotides (map numbers 456 to 695) from 


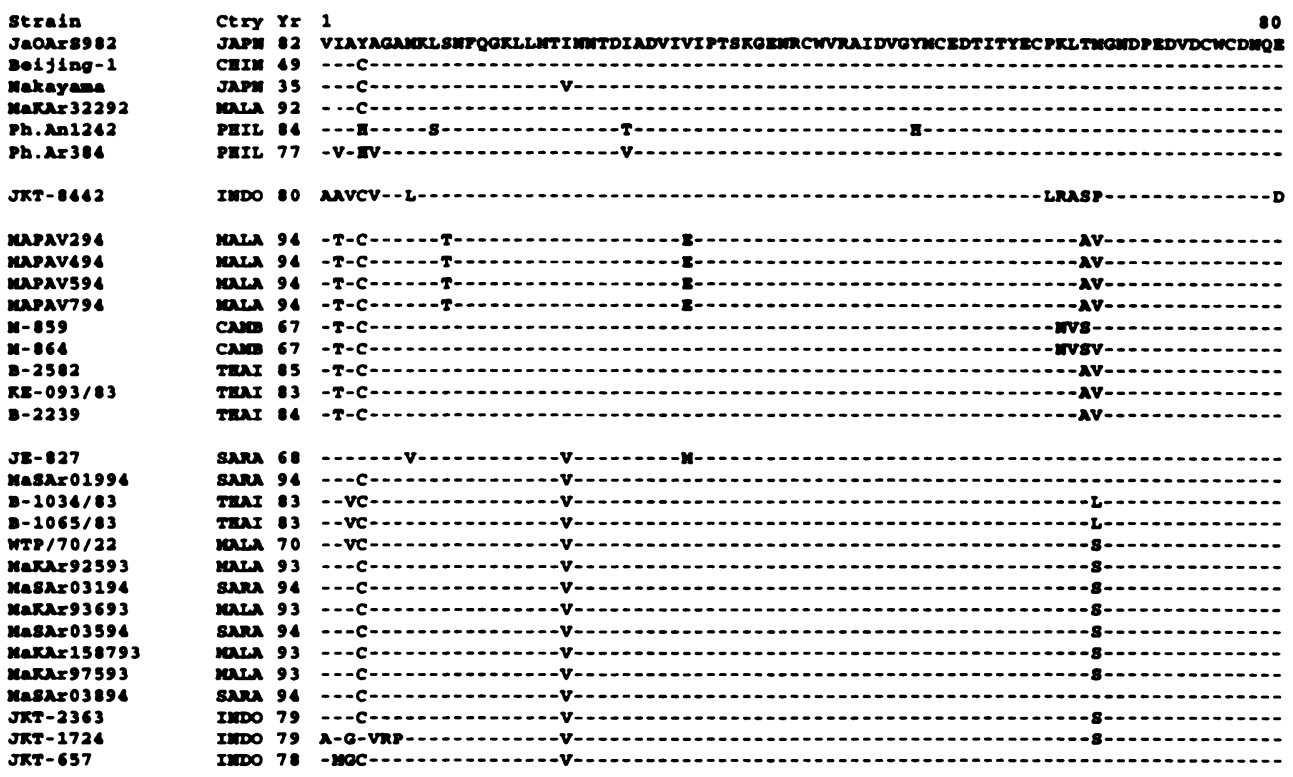

FIGURE 3. Amino acid sequences deduced from the 240 nucleotides used for determining genetic relatedness among 31 Japanese encephalitis virus isolates. See Figure 2 for other information.

each JEV strain was compared with all other strains for similarity. By pairwise alignment and statistical comparison of nucleotide differences, a dendrogram of strain relationship was generated by the PILEUP computer program (Genetics Computer Group, Madison, WI). ${ }^{15}$

\section{RESULTS}

Nucleic acid sequences of the pre-M gene region. $\mathrm{Nu}$ cleic acid sequences of the pre-M gene region were obtained for $12 \mathrm{JEV}$ isolates from Malaysia and compared with the corresponding published sequence of the JaOArS982 strain of JEV (Figure 2). No difference in the nucleotide sequences was observed among the four JEV strains isolated from Ipoh, Perak in 1994. These strains differed from earlier isolated strains from Malaysia, JE-827 from Sarawak in 1968, WTP/70/22 from Kuala Lumpur in 1970, and MaKAr32292 from Sabak Bernam, Selangor in 1992, by 34 (14.2\%), 34 (14.2\%), and $35(14.6 \%)$ nucleotides, respectively. The four JEV strains isolated from Sepang, Selangor in 1993 and the four JEV strains isolated from Sarawak in 1994 were closely related to each other, with a divergence of $0.4-9.2 \%$. The WTP/70/20 strain differed from these eight strains isolated from Sepang, Selangor in 1993 or from Sarawak in 1994 by 14 (5.8\%, MaKAr158793) to 18 (7.5\%, MaKAr97593) nucleotides. The JE-827 strain differed from these eight strains by 10 (4.2\%, MAS01994) to 30 (12.5\%, MaKAr97593) nucleotides. The sequence divergence of MaKAr32292 strain to the eight strains ranged from 10\% (MAS03194 and MAS03894) to $12.1 \%$ (MaKAr 158793). The four JEV strains isolated from Ipoh, Perak in 1994 differed from these eight strains by 31 (12.9\%, MAS01994) to 38 (15.8\%, MaKAR97593) nucleotides.

Amino acid sequence divergence in the pre- $M$ gene region. Eighty amino acids are encoded in the pre-M region of JEV. A maximum amino acid sequence divergence of $10 \%$ (eight amino acids) was observed among the $15 \mathrm{JEV}$ strains isolated from Malaysia including three previous isolates, JE-827, WTP/70/22, and MaKAr32292 (Figure 3). Amino acid sequence divergence between JEV strains was lower than nucleotide sequence divergence because most nucleotide changes were silent as reported in previous studies. 5.6 Most of the amino acid changes were observed in more than two strains isolated from defined regions in Malaysia. For example, all eight strains isolated from Sepang, Selangor in 1993 or from Kampong Sebintin, Sarawak in 1994 encoded valine instead of isoleucine, which is present in JaOArS982 at amino acid position 21 , and six of them encoded serine instead of methionine at the position 65 .

Dendrogram and sequence similarity. The relatedness of $\mathrm{JE}$ viruses examined in this study are presented in the form of a dendrogram (Figure 4). The $12 \mathrm{JEV}$ strains were classified into two genotypes that were different from MaKAr32292 isolated from Sabak Bernam, Selangor in 1992. The four JEV strains from Sarawak in 1994 and the four JEV strains from Sepang, Selangor in 1993 were classified into one genotype that included earlier isolated strains from Malaysia, JE-827 from Sarawak in 1968 and WTP/70/ 22 from Kuala Lumpur in 1970. The four JEV strains from Ipoh, Perak in 1994 were classified into another genotype that included JEV strains isolated from northern Thailand and Cambodia.

\section{DISCUSSION}

It is known that JE and JEV exist widely in Asia, including Japan, China, Taiwan, Korea, the Philippines, Southeast Asia, and India. ${ }^{1} 2$ As a typical arbovirus, JEV is maintained in nature by alternative growth in vertebrate hosts and arthropod vectors. Among vertebrate hosts susceptible to JEV, some avian species as well as swine are the most important amplifier because of their significant viremia following JEV infection, large numbers of population, high turnover rate, and preferential feeding by the vectors. ${ }^{2}$ The most important 


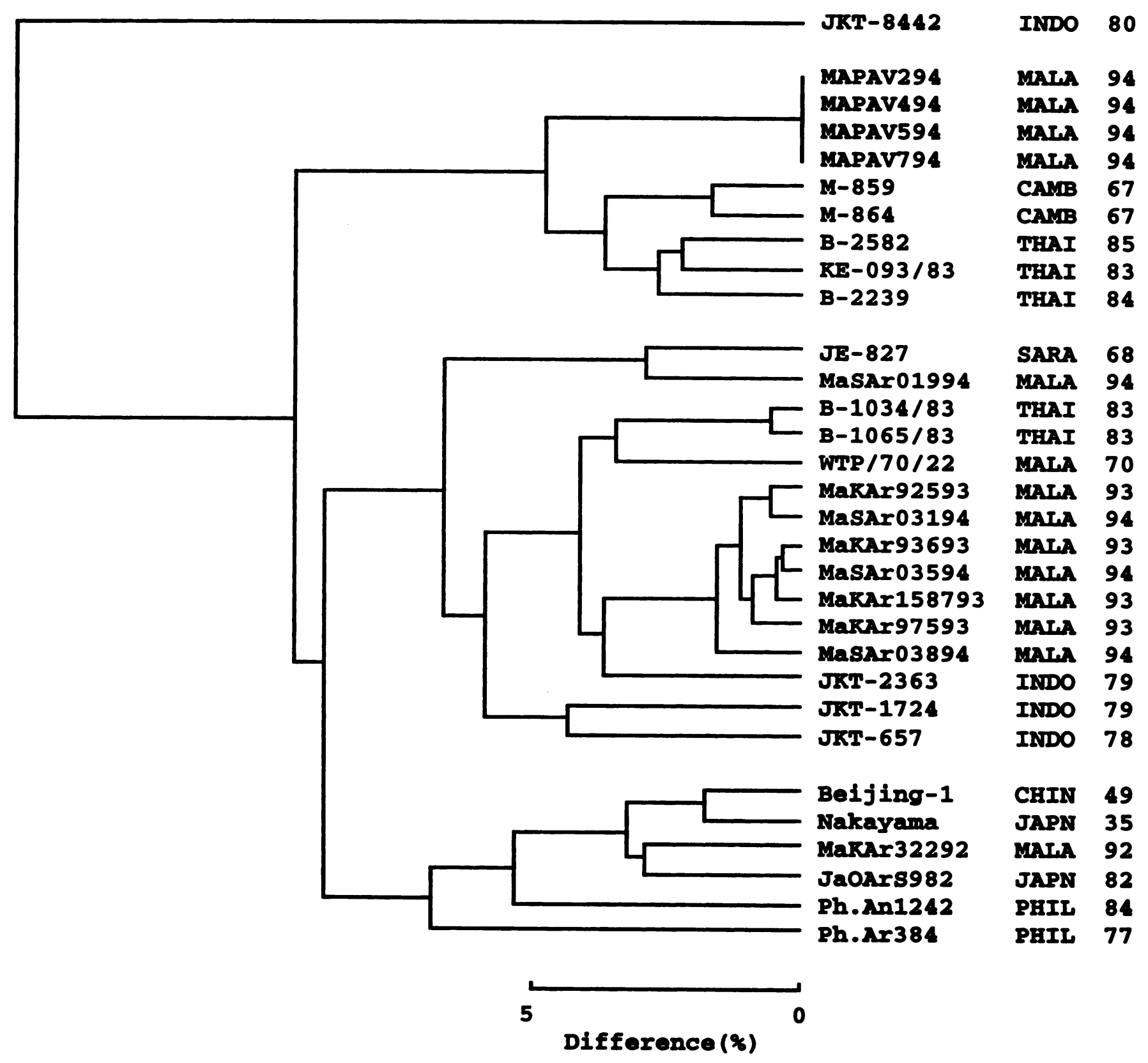

FIGURE 4. Dendrogram of genetic relationships of 31 Japanese encephalitis virus isolates from different geographic areas of Asia. The nucleotide sequence divergence between any two strains is twice the distance along the $x$-axis to the node that connects them. See Figure 2 for other information.

vector species is Culex tritaeniorhynchus and related mosquitoes that breed in watered rice fields. Most of the monsoon areas in these Asian countries have the climatic condition of sufficiently high temperature during summer and precipitation during rainy season, allowing for rice cultivation in watered paddy fields. Swine raising is quite common in this area, except for Moslem areas, including Malaysia.

There are two distinct patterns of JEV transmission, epidemic and endemic. ${ }^{5}$ In general, the disease is epidemic in regions with marked seasons and is maintained under endemic form in tropical regions. Japanese encephalitis is neither classified as an entity in the Malaysian Medical records system nor is it a reportable disease but is grouped as viral encephalitis. The number of clinically diagnosed viral en- cephalitis cases reported to the Ministry of Health of Malaysia from 1977 to 1988 ranged from 37 to 92 per year. ${ }^{16}$ Among them, serologically confirmed JE cases ranged from 10 to 35 per year. This disease occurs in almost every state in Malaysia, the greater number of cases occur in Penang, Perak, Selangor, and Johore in West Malaysia and Sarawak in East Malaysia. Possible factors contributing to the occurrence of $\mathrm{JE}$ in these states may be high population densities and pig farming activities. There is no definite seasonal pattern and JE cases have been observed to occur year round. In our present study, four JEV strains isolated in Sarawak in 1994 and four JEV strains isolated in Sepang, Selangor in 1993 were classified into one genotype that included earlier Malaysian isolates, JE-827 from Sarawak in 1968 and 
WTP7022 from Kuala Lumpur in 1970. Four JEV strains isolated in 1994 in Ipoh, Perak (the area nearest to Thailand compared with the other three areas studied) were classified into another genotype that included JEV strains isolated from northern Thailand and Cambodia. In our previous report, ${ }^{10} 10 \mathrm{JEV}$ strains isolated in Sabak Bernam, Selangor in 1992 were classified into the largest genotype that includes strains isolated in temperate regions such as Japan, China, and Taiwan. These data indicate that at least three genotypes of JEV have been circulating in Malaysia. It has been shown that JEV isolates from the same geographic region and time period are very similar, but that genetic variation occurs among strains from diverse regions or different time periods in the same region. 5.6

It has also been reported that Vietnamese strains isolated between 1964 and 1988 belong to the largest genotype that includes strains isolated in temperate regions. ${ }^{17}$ The data suggest that JEV genotypes do not displace easily, despite the relative geographic proximity of Thailand and Cambodia. The area in Sepang District, Selangor studied in 1993 is 40 $\mathrm{km}$ south of Kuala Lumpur; this is a pig farming area in which pig sties are surrounded by oil palm trees. The area in Kampong Pasir Panjang, Sabak Bernam District, Selangor studied in 1992 is $80 \mathrm{~km}$ northwest of Kuala Lumpur; ${ }^{18}$ here the land is flat, consisting mainly of rice fields. The JEV strains studied in our investigations might have evolved from a common ancestor and circulated in mosquitoes (overwintering adults or transovarially infected eggs) in defined geographic regions in Malaysia for many years. Alternatively, strains classified into the genotype including strains isolated in temperate regions might have been introduced into Malaysia recently by migrating birds or by international transportation systems such as jet airplanes because in tropical countries such as Malaysia, susceptible animal and mosquitoes populations are available in all seasons, and JEV can expand into new regions.

Acknowledgments: We thank the Director of the Institute for Medical Research (IMR) for permission to publish this paper. We also thank Dr. Sharifah Syed Hassan (Veterinary Research Institute, Perak) for providing four animal sera from Perak and Dr. M. S. Chang for providing the mosquito pools from Sarawak. The nucleotide sequence data reported in this paper will appear in the DDBJ, EMBL, and GenBank nucleotide sequence databases with the following accession number: D83922-D83943.

Financial support: This study was supported by the IMR-Japan International Cooperation Agency (JICA) Collaborative Research Project on Tropical Diseases in Malaysia, conducted during the period from January 1993 to December 1995. This work was partly funded by the Malaysian Ministry of Science, Environment and Technology Fund: 3-08-01-100/IMR 94-026.

Authors' addresses: Hideaki Tsuchie, Takashi Wada, and Takashi Kurimura, Research Institute for Microbial Diseases, Osaka University, 3-1 Yamadaoka, Suita, 565 Osaka, Japan. Kazumasa Oda and Hiroshi Tanaka, Japan International Cooperation Agency, 2-1-1 Nishishinjuku, Shinjuku, Tokyo. Indra Vythilingam, Ravindran Thayan, Balasubramaniam Vijayamalar, and Mangalam Sinniah, Institute for Medical Research, Jalan Pahang, 50588 Kuala Lumpur, Malaysia. Jasbir Singh, Veterinary Research Institute, 59 Jalan Sultan Azlan Shah, 31400 Ipoh, PO Box 369, Perak Darul Ridzuan, Malaysia. Akira Igarashi, Institute of Tropical Medicine, Nagasaki University, 1-12-4 Sakamoto, Nagasaki, 852 Japan.
Reprint requests: Hideaki Tsuchie, Research Institute for Microbial Diseases, Osaka University, 3-1 Yamadaoka, Suita, 565 Osaka, Japan.

\section{REFERENCES}

1. Umenai T, Krzysko R, Bektimirov TA, Assaad FA, 1985. Japanese encephalitis: current worldwide status. Bull World Health Organ 63: 625-631.

2. Igarashi A, 1992. Japanese encephalitis-virus, infection, and control. Kurstak E, ed. Control of Virus Diseases. New York: Marcel Dekker, Inc., 309-342.

3. Burke DS, Leake CJ, 1988. Japanese encephalitis. Monath TP, ed. Arboviruses :Epidemiology and Ecology. Volume III. Boca Raton, FL: CRC Press, 63-92.

4. Hasegawa H, Yoshida M, Fujita S, Kobayashi Y, 1994. Comparison of structural proteins among antigenically different Japanese encephalitis virus strains. Vaccine 12: 841-844.

5. Chen WR, Tesh RB, Rico-Hesse R, 1990. Genetic variation of Japanese encephalitis virus in nature. J Gen Virol 71: 29152922.

6. Chen WR, Rico-Hesse R, Tesh RB, 1992. A new genotype of Japanese encephalitis virus from Indonesia. Am J Trop Med Hyg 47: 61-69.

7. Ni H, Barrett DT, 1995. Nucleotide and deduced amino acid sequence of the structural protein genes of Japanese encephalitis viruses from different geographical locations. J Gen Virol 76: 401-407.

8. Vythilingam I, Oda K, Chew TK, Mahadevan S, Vijayamalar B, Morita K, Tsuchie H, Igarashi A, 1995. Isolation of Japanese encephalitis virus from mosquitoes collected in Sabak Bernam, Selangor, Malaysia in 1992. J Am Mosq Control Assoc 11: 94-98.

9. Igarashi A, 1978. Isolation of a Singh's Aedes albopictus cell clone sensitive to dengue and chikungunya viruses. J Gen Virol 40: 531-544.

10. Tsuchie $H$, Oda $K$, Vythilingam I, Thayan R, Vijayamalar B, Sinniah M, Hossain MM, Kurimura T, Igarashi A, 1994. Genetic study of Japanese encephalitis viruses in Malaysia. Jpn J Med Sci Biol 47: 101-107.

11. Sumiyoshi H, Mori C, Fuke I, Morita K, Kuhara S, Kondou J, Kikuchi Y, Nagamatsu H, Igarashi A, 1987. Complete nucleotide sequence of the Japanese encephalitis virus genome RNA. Virology 160: 497-510.

12. Hashimoto $H$, Nomoto $A$, Watanabe $K$, Mori $T$, Takezawa $T$, Aizawa C, Takegami T, Hiramatsu K, 1988. Molecular cloning and complete nucleotide sequence of the genome of Japanese encephalitis virus Beijing-1 strain. Virus Genes 1: 305317.

13. Chomczynski P, Sacchi N, 1987. Single step method of RNA isolation by guanidium thiocyanate phenol chloroform extraction. Anal Biochem 162: 156-159.

14. Ogawa S, Shrestha MP, Rai SK, Parajuli MB, Rai JM, Ghimire SC, Hirai K, Nagata K, Tamura T, Isegawa Y, Okuno Y, Ueda $S, 1992$. Serological and virological studies of Japanese encephalitis in the Terai region of Nepal. Southeast Asian $J$ Trop Med Public Health 23: 37-43.

15. Feng DF, Doolittle RF, 1987. Progressive sequence alignment as a prerequisite to correct phylogenetic trees. J Mol Evol 25: 351-360.

16. Sinniah M, 1989. A review of Japanese-B virus encephalitis in Malaysia. Southeast Asian J Trop Med Public Health 20: 581-585.

17. Huong VTQ, Ha DQ, Deubel V, 1993. Genetic study of Japanese encephalitis viruses from Vietnam. Am J Trop Med Hyg 49: 538-544.

18. Vythilingam I, Singh KI, Mahadevan S, Zaridah MS, Ong KK, Abidin HZ, 1993. Studies on Japanese encephalitis vector mosquitoes in Selangor, Malaysia. J Am Mosq Control Assoc 9: 467-469. 